2015

\title{
Faculty Viewpoints on Teaching Quantway®
}

\author{
Heather Howington \\ University of North Georgia - Gainesville Campus, Heather.howington@ung.edu \\ Thomas Hartfield \\ University of North Georgia - Gainesville Campus, thomas.hartfield@ung.edu \\ Cinnamon Hillyard \\ University of Washington Bothell, chillyard@uwb.edu
}

Follow this and additional works at: https://digitalcommons.usf.edu/numeracy

Part of the Curriculum and Instruction Commons, Higher Education Commons, and the Science and Mathematics Education Commons

\section{Recommended Citation}

Howington, Heather, Thomas Hartfield, and Cinnamon Hillyard. "Faculty Viewpoints on Teaching Quantway®." Numeracy 8, Iss. 1 (2015): Article 10. DOI: http://dx.doi.org/10.5038/1936-4660.8.1.10 


\title{
Faculty Viewpoints on Teaching Quantway®
}

\begin{abstract}
Quantway is a quantitative reasoning-based pathway for developmental math that has been developed as an alternative to the traditional remedial algebra sequence. To explore the experiences of faculty involved with Quantway, we interviewed eight individuals who have taught the course in the past year to survey their attitudes and opinions about students in their classes, the materials and pedagogies in use, and the collegial interaction of networked faculty. Faculty were selected with the intention of gathering a broad set of opinions resulting from differences of location, experience, and other factors. In this paper, we summarize those interviews by identifying common themes reported by the faculty that highlight strengths and challenges of teaching Quantway. Themes include perceptions about changes in student engagement and attitudes as well as changes in their own mindset; the evolution of teaching strategies and materials used inside and outside the classroom; and the relevance of connections between faculty at different institutions involved in the project.
\end{abstract}

\section{Keywords}

developmental math, faculty attitudes, mindset, quantway, algebra

Creative Commons License

(c) (1) (9)

This work is licensed under a Creative Commons Attribution-Noncommercial 4.0 License

\section{Cover Page Footnote}

Heather Howington is an assistant professor of mathematics and Math Learning Support Liaison at the University of North Georgia, Gainesville campus. She has taught a wide variety of courses including Developmental Math, Quantitative Skills and Reasoning, Mathematical Modeling, College Algebra, Precalculus, Brief Calculus, and Calculus. Heather has been teaching Quantway since 2012 and serves as a Faculty Mentor for new faculty. Her interests include motivating students' success in their path from developmental mathematics to quantitative literacy.

Thomas Hartfield is an assistant professor of mathematics at the University of North Georgia, Gainesville campus. He teaches developmental and core math courses with a focus on using relevant instructional media in and out of the classroom. Thomas was awarded a best practices award by Gainesville State College in 2011 for his work with podcasting and has a wealth of experience working with instructional technology.

Cinnamon Hillyard is an associate professor of mathematics in the School of Interdisciplinary Arts and Sciences at the University of Washington Bothell. She has also worked as a Senior Associate for the Carnegie Foundation and has held leadership positions in the NNN and SIGMAA-QL. She teaches mathematics (including Quantway), statistics, and interdisciplinary research courses. Her research focuses on how people use quantitative information to make decisions and how undergraduate education can foster the development of quantitative literacy.

This article is available in Numeracy: https://digitalcommons.usf.edu/numeracy/vol8/iss1/art10 


\section{Introduction and Background}

Getting students through college has been a growing concern over the past decade. A major stumbling block for many students is their math requirements, and traditionally students have had limited choices in meeting these requirements. Some schools allow students to complete one of several different college-level options by offering a precalculus course, a quantitative reasoning course, or a statistics course. Yet, many of these same schools still require students either to pass an algebra placement test or complete a sequence of developmental math courses culminating in intermediate algebra. Students starting two or more levels below college mathematics are less likely to graduate than their peers with otherwise similar background (Attewell et al. 2006). A recent report by the Community College Research Center focusing on schools participating in the Achieving the Dream ${ }^{1}$ initiative found that $60 \%$ of college students place in this developmental math sequence nationwide and only $80 \%$ of those students make it to their college-level course (Bailey et al. 2010). Not only is getting through these courses a challenge but the existing sequence of developmental math involving extensive algebra remediation has not been clearly shown to have a significant impact on degree attainment (Attewell et al. 2006: 912-914), and traditional college algebra sequences fail to meet the needs of most students who are taking those courses (Gordon 2008). Beyond the classroom, students may not meaningfully benefit in their careers or everyday lives from the repeated exposure to mathematics in the traditional sequence.

In addition to Achieving the Dream and the Community College Research Center, other national organizations and researchers have cited the need for new approaches for developmental mathematics for college students. Complete College America (2013) provides evidence that streamlining the path to completion and aligning the mathematics requirements with degree needs are essential components of successful remediation programs. A Learning Works report (Burdman 2013) advocates that multiple pathways through developmental math is a successful strategy for helping students achieve their college degrees because "the standard math sequence aligns with few students' career aspirations" (p. 8). A report from the Mathematical Association of America (Ganter and Haver 2011) acknowledges the need for multiple pathways but notes that "no mathematics department can possibly offer a different mathematics course for majors in each of the different disciplines represented on its campus-making the need to rethink and revise the most popular introductory mathematics courses

\footnotetext{
${ }^{1}$ Achieving the Dream: Community Colleges Count. See the fact sheet at: http://www.capitalcc.edu/docs/atd/atd_initiative.pdf
} 
even more critical” (p. 40). A report from the American Mathematical Association of Two Year Colleges (AMATAYC) also supports the vision to address the needs of diverse students and encourages integrating "quantitative literacy outcomes into all mathematics courses and into coursework across all disciplines" (Blair 2006: 49). Finally, Hillyard (2012) recommends that numeracy educators "work deliberately with math departments and funding agencies to integrate numeracy more explicitly in high-volume, entry-level mathematics courses” (p. 16).

In response to these calls for action, multiple groups have developed alternative pathways for developmental math students. Examples include AMATYC's New Life Project (Rotman 2013) and The Charles A. Dana Center's New Mathways Project. $^{2}$ Of direct relevance to this paper, the Carnegie Foundation for the Advancement of Teaching has created two pathways for developmental mathematics students to access college-level mathematics. Carnegie's Statway ${ }^{\circledR}$ program $^{3}$ offers a year-long college-level statistics course in which algebra topics that are needed to support the statistical topics are infused into the curriculum. The second pathway, Quantway ${ }^{\circledR}$, is a quantitative reasoning course meant to replace the traditional developmental math sequence involving introductory and intermediate algebra.

Quantway was specifically developed to address these issues by implementing a quantitative reasoning curriculum that gets students through their math requirements in a shorter time while providing them the necessary mathematical and quantitative reasoning skills both to complete their college degrees and to use in daily life. Quantway targets the group of students discussed earlier that place two or more levels below a college-level mathematics course. Quantitative reasoning scholars, mathematics faculty from a diverse set of undergraduate institutions, and educational researchers met together to determine a set of rigorous learning goals for the pathway. These goals fell under six categories: Quantitative Literacy, Numeracy Skills, Proportional Reasoning, Algebraic Reasoning, Mathematical Modeling, and Statistical Thinking. This group agreed on a set of curriculum design principles based in inquiry-based learning that utilizes rich contextual problems to satisfy the learning goals. A complete list of the design principles and learning objectives can be found on Carnegie’s Website for the Quantway program. ${ }^{4}$

\footnotetext{
2 Information about the Dana Center's Mathways Project can be found at http://www.utdanacenter.org/higher-education/new-mathways-project/

${ }^{3}$ Information about Carnegie's Statway program can be found at http://www.carnegiefoundation.org/statway

${ }^{4}$ Quantway sample materials including the learning objectives and design principles can be downloaded as a zip file from: http://www.carnegiefoundation.org/quantway/quantway-reference$\underline{\text { materials }}$
} 
The creators of the Quantway pathway incorporated a variety of components to ensure student success. First, Quantway includes multiple authentic texts for students to sift through and asks them to communicate their thinking in words. To support students in these reading and writing tasks the Quantway materials include Language and Literacy routines for both students and faculty. Second, students may struggle to be successful in a mathematics course because they have feelings of academic inadequacy, do not appreciate the value of mathematical learning, and/or lack college behavior skills. To help with these issues Quantway uses Carnegie's Productive Persistence ${ }^{5}$ materials to support students in the class. The materials include routines for faculty to ensure successful group work, assist students in changing their mindsets about mathematics, and create a sense of belonging in the course. A third feature is attention to faculty development. The curriculum, language and literacy, and productive persistence routines expect faculty to avoid a traditional instructional approach in the classroom. Deliberate attention is being given to faculty teaching Quantway to ensure they have the resources, skills, and support they need to deliver the curriculum. This training includes face-to-face workshops, online training materials, and coaching from a peer who has experience teaching the course.

As the pathway matures, Quantway is using a collaborative paradigm to develop and improve the materials and professional development. Faculty engaged in the pathway can benefit from not having to work in isolation but, instead, by joining together in a national Network Improvement Community (NIC) to learn from and support each other in their work. The NIC includes faculty, administrators, student services staff, and institutional researchers from each college in the Quantway consortium. NIC members can join monthly calls to discuss issues and are encouraged to attend a national forum each July to work together on common problems and receive additional training. Additionally, the NIC uses the tools of improvement science ${ }^{6}$ to continually improve Quantway. This research methodology uses data from each school teaching Quantway to improve the materials and teaching methods in the pathway. Initial evidence collected from participating colleges indicates that this approach has been successful. Out of 1820 students that were enrolled in a Quantway course in the first two years of the pathway, 960 successfully completed the course with a $\mathrm{C}$ or higher, a pass rate exceeding 50\%. Historically for these same colleges, only $20 \%$ of students of similar placement would exit developmental math in one year (Van Campen et al. 2013). Successes have not come without substantial changes for everyone involved. Faculty have had to change their mindset about what it means

\footnotetext{
${ }^{5}$ For more information on Carnegie's Productive Persistence initiative see: http://www.carnegiefoundation.org/productive-persistence

${ }^{6}$ Information about improvement science approach to education can be found at: http://www.carnegiefoundation.org/improvement-research/approach
} 
to teach mathematics and help students discover a new way of approaching and thinking about mathematics.

Others have advocated for a quantitative reasoning approach in teaching algebra (Gaze 2014, Madison 2014). Yet, little is written about how such a curriculum works across multiple campuses in varied classroom settings. Studying the Quantway project provides a unique opportunity to investigate the multiple instructors' successes and challenges in implementing a new mathematics pathway that uses quantitative reasoning and active-learning pedagogies to develop algebraic concepts. In this paper, we specifically explore how teaching Quantway was experienced by faculty who had previously taught more-traditional developmental and college-level mathematics courses.

\section{Methods}

Two of the authors interviewed eight faculty members across five states teaching Quantway. These faculty represented $17 \%$ of the total faculty teaching at least one section of the course in the 2012-2013 academic year. Participants were selected to ensure diversity in the following ways: both male and female instructors (2 men and 6 women); instructors from institutions in each state involved in Quantway (Georgia, Minnesota, New York, Ohio, and West Virginia); instructors from colleges offering either many sections or just a few sections (ranging from over thirty sections per semester to as few as three sections per year); both long-time and relatively new instructors (from three to thirty years of teaching experience); and instructors who had been involved from the beginning of the program as well as instructors with less than one year of Quantway teaching experience. The following questions were asked to each interview subject:

- What has been the most challenging about teaching Quantway?

- What has been the most exciting/rewarding thing for you?

- How has teaching in a more applied setting changed your mindset about teaching mathematics?

- How have your students reacted to this new type of math class (in context with collaborative learning)?

- What types of classroom management skills have you needed to develop or improve? (e.g., issues around group work, students getting emotionally charged around issues, getting students to participate in discussion, getting students to read carefully, etc.) 
- How important is it to be part of a national networked community? (e.g., training opportunities, professional development, conversations with other colleagues, support systems, etc.)

- How long have you been in the Quantway program?

- Is there anything else you would like to report about your Quantway experience?

Each interview took about 45 minutes and was conducted over the phone. The interviewers took detailed notes. The third author reviewed the interview notes using a content analysis framework to identify common themes. The researchers then discussed the themes to ensure consensus and reduce bias. In the results below, we labeled the faculty with the numbers \#1 through \#8 but give no additional identifiers in order to preserve their confidentiality. The Quantway network works so closely together that we believe they could easily identify each other if more details were provided about each of the eight interviewees.

\section{Research Results}

Six themes emerged from our interviews. Although some themes are similar in language and scope to the questions asked, frequently the interviewed faculty extended their comments beyond the nature of each question which permitted greater nuance in summarizing the results. Each specific theme was addressed by at least seven of the eight individuals interviewed using the language of their responses as guidance.

\section{Theme 1: Faculty report significant changes in student attitudes, perceptions, and engagement as students go through Quantway}

All faculty interviewed reported that seeing students actively engaged with the curriculum was one of the most rewarding parts of teaching Quantway. As stated by Faculty \#1, "most students appreciate learning math which they see they will actually use." Students enjoy learning mathematics a different way and see a purpose in taking the course. Faculty \#3 noted that her students in Quantway "are more participatory, more vocal, and more animated," and she feels frustrated with students in other non-Quantway sections "because they don't ask questions or try to figure things out."

With the use of contextual problems, faculty have observed that students begin to read questions more carefully, question the sources of the numbers used in problem situations, and debate when an answer is reasonable. Faculty \#4 observed this as a benefit because "students are getting a different perspective on 
math and are more receptive to seeing the practicality and application outside the classroom." Students may begin to experience the proverbial "light bulb" effect as connections with mathematics are developed. Faculty \#8 explained "some students gained a confidence in being able to learn mathematics for the first time [to the degree] that they even changed to a major that required more math."

These benefits have not come without a variety of challenges, however. Topics such as gun violence, environmental sustainability, blood alcohol levels, cancer, and other "hot-button" issues can cause students to become emotionally charged; faculty reported that the focus on these topics would frustrate some students. Dealing with these emotions was new for both the student and the instructor in a math class. Faculty \#3 stated:

\begin{abstract}
I have a cancer survivor in my class and she reacted to information in the class by saying she didn't want to know these things. Other students had reactions to topics as well, but it has gotten better. When things get emotionally charged, I let [students] vent (and) explain their part. Then I tell them we have to continue.
\end{abstract}

Beyond addressing potentially sensitive areas, faculty reported that the studentcentered approach was difficult in some classes. Faculty \#4 commented that "some students have an extremely low motivation level despite my efforts and I have had to rely on a handful of cooperative and attentive students who were effective as group leaders." Some students find the material confusing at first and would rather the instructor just tell them what to do instead of working together or relying upon their group members. The social responsibility of the course was a challenge as students "were a little afraid of groups where not everyone is participating, where some are doing all the work and some are being lazy" according to Faculty \#2. She continued, saying "I try to convince them early on that this is a good method and they are buying into this."

\title{
Theme 2: Quantway affected faculty mindsets about effective pedagogies for teaching mathematics
}

Many faculty reported that learning how to teach with the new Quantway pedagogy was one of the most challenging parts of the program. "We are taught to lecture and have students mimic," said Faculty \#2, who continued, "I had to relearn how to make the whole group work." Quantway was developed to engage students in a manner similar to inquiry-based learning which requires that instructors cede substantial control on delivering and developing information. Nearly every faculty member spoke about how this change in approach impacted them directly, and Faculty \#2 even addressed how a colleague found it difficult: "I was training someone and they were observing my class. Later I found out he was telling [my students] how to do it as opposed to letting them figure it out."

This new instructor role included learning how to let students struggle with the material when the struggle was productive. This was described as follows: 
Faculty \#1: I needed to get used to letting students struggle without telling them how to do the problems and how to provide assistance when the struggle was unproductive.

Faculty \#2: I have a student who cries; she puts her head down and sobs. I talk to her but I'm not sure what to do.

Faculty also had to learn how to be uncomfortable with not knowing how a lesson might emerge. The new faculty members reported that they spent significant planning time trying to anticipate the questions that students might have during the lessons. Faculty \#7 reported that this used to be the biggest challenge: "I was keeping one step ahead trying to be ready for what the students would ask." Faculty \#4 elaborated: "When preparing, I spend more time thinking of alternatives that students will say or do." This, in turn, forces faculty to spend time thinking more about students thinking. More-experienced faculty reported they realized they couldn't be prepared for every possible response. Instead, they learned how to be comfortable with not knowing and possibly "failing" at times. Faculty \#1 had learned to look at it as a positive challenge: "The applied setting is much more interesting and fun to teach since I never know what my students will come up with.” In some cases, faculty recognized that moving out of their own comfort zones in teaching gave them more appreciation of their students' struggles with new material. Comments like the ones below illustrate this:

Faculty \#5: I have more appreciation for the struggles that students have because I was also struggling with the new way of teaching this class.

Faculty \#3: It has really helped me out as a teacher. I understand how students are processing the information better.

Faculty also reported taking these same pedagogies back to their other mathematics courses. Teaching Quantway changed the way they think about teaching mathematics and they saw new ways of learning mathematics. Faculty members described using a more student-centered approach in other classes:

Faculty \#2: When I'm teaching my 'normal' classes I don't lecture anymore. I do similar approaches in my other classes and have students discover and struggle on their own.

Faculty \#1: I would love to switch all of our developmental level courses to applied setting and to incorporate more applied contexts in our STEM math courses.

Faculty \#6: [Quantway] has a large impact on how I think about teaching overall and gives me hope for a new way for teaching mathematics.

Faculty \#3: [Quantway] gives me another way to teach math; a different way to look at teaching math.

\section{Theme 3: Quantway faculty developed new teaching skills}

The change in pedagogy introduced new challenges in classroom management for faculty. Managing classroom time, leading discussions involving the context of the materials, organizing group work, and encouraging student attendance were 
new for many faculty members who were more familiar with the absolute control offered by carefully planned lectures. Amongst the comments:

Faculty \#3: I like to explain things in a lot of different ways but this time I have to keep my mouth shut. That's very different for me.

Faculty \#5: I've had to get used to a lot of silence at the beginning of class while students are struggling. I want to push more, but I have to let them do the learning.

Faculty \#8: I am so used to teaching by lecturing and being in control. I had to get used to going with the flow and not always knowing what to expect.

Faculty found that some students did not want to participate. Sometimes they would come but not engage with the material or their group, and sometimes they would not come at all. Faculty noted:

Faculty \#3: I had a group that refused to go along with the class and they wanted everything handed to them and I told them the class couldn't be that way.

Faculty \#1: A few students find it confusing and just want to be told what to do.

In previous math classes, if students didn't come to class or engage in group work or discussions, the consequences might be small. Since Quantway is designed around student discovery and interaction, students may be quickly impacted by missing lessons or not contributing to their group. Engaging students in their own learning is important, as noted by Faculty \#4 who stated "students have to be invested in their own learning because if they are not willing to put forth the necessary effort, they can quickly get lost."

As mentioned in theme 1, Quantway material is purposefully designed to introduce the mathematics through authentic contexts which sometimes leads to students being personally vested in the question. Faculty reported that students could easily get caught up around the controversy of the topic. When these diversions occur, time management often became an issue:

Faculty \#6: It was hard when a person gets off-base on topics" and "personal issues can take students off of the 'math track.'

Faculty \#7: I had to learn how and when to intervene. A difficulty has been how to balance group conversations with class conversations. I encourage them to talk to each other and explain their thoughts and ideas, and then I have to interrupt them to bring the class back together.

One example given by Faculty \#4 occurred when students were working on a lesson about designing a garden in order to illustrate some geometric principles. One student made a stereotypical statement about the nationality of many gardeners in their region. Several students in the class were deeply offended by this comment. From Faculty \#4: "I had to diffuse some raw feelings during that class meeting and keep an eye on relationships in the future. It is rare for me to have the same issues in my traditional classes." 


\section{Theme 4: Collaborative learning is very rewarding but takes purposeful and thoughtful work to ensure the benefits emerge in the classroom}

As noted previously, an integral part of the Quantway pedagogy depends on group work. This collaborative learning emphasis provided both challenges and opportunities for both faculty and students. New faculty were skeptical that all students would engage and contribute to the group work. Faculty \#7 noted:

I don't think my students liked the idea of group work at first. It feels like they have a lot of responsibility-to themselves and the group-but they usually get to like working together. I have a lot of respect for the students trying to get along with each other.

Setting up and managing groups were particularly difficult challenges for faculty. They had to develop new skills in working with struggling groups. Faculty had to learn how to deal with students who "wanted to do all the work", students who "just wanted to copy the answers," students who preferred to "work alone," and students who didn't want to talk. Situations that arose are illustrated by the following comments:

Faculty \#2: I do need to get them to participate.... If the group is not working, I have to decide when and who to change.

Faculty \#4: Students sometimes get distracted and do not use their time well.

Faculty \#5: I had to tell students to speak up and they can actually be as loud as they need to.

Faculty \#6: I have had to associate some in-class activity points with group participation to get some groups more involved.

However, once over these hurdles, group work had many exciting rewards. A sense of community developed where students supported each other both within and outside the class. Faculty reported that the group work became more productive as they developed the skills to manage those groups. This was exemplified by the following comments:

Faculty \#3: My students like working together to figure stuff out.

Faculty \#7: Students were nice and supportive to each other in this new learning environment.

Faculty \#1: They get to know each other which helps with retention.

Faculty \#2: Students who said they never thought they'd like coming to a math class say they like being there.

Faculty \#8: One of my students was in a motorcycle accident the week of final exams, and in another class one student had to withdraw after midterm to go on bed rest for preterm labor. On both occasions, the other students signed cards, sent emails, and visited these students outside of class. I have never seen that in any other class I've taught. 
Several faculty acknowledged the students' preferences for this learning environment. Faculty \#6 subbed in a subsequent course and commented on how shocked he was at how much the students expressed their excitement about being able to choose to take the class over a traditional class because of the group work.

\section{Theme 5: Evolving and flexible materials are valuable resources in teaching the curriculum}

Quantway is considered an evolving project that learns using the tools of improvement science, and the materials are co-owned by the collaborator colleges. Faculty \#2 has been involved from early on in the creation and evolution of materials and commented "we [have] spent so much time developing materials-and so are other colleges-and I think it is getting better." Faculty teaching Quantway are invited to join subnetworks (subnets) that work on evolving aspects of the materials. Faculty \#5 and Faculty \#8 joined the assessment subnetwork to get involved in creating different types of assessment questions for exams. From Faculty \#7: "I joined the FIT (Framework for Improving Teaching) subnet to develop and test lessons that support a richer diversity of student ideas and promote effective discussion."

Faculty are encouraged to adapt the national materials for their unique student body. Having collaboratively created lessons that can be augmented, contracted, or otherwise changed was a positive for multiple instructors interviewed, but this flexibility does require an investment in time as noted by Faculty \#1: The most challenging aspect has been to tweak the lessons to better fit the time available and my students' capabilities."

However, with the continual modification of a living curriculum, the platform for the materials has not always stayed current. Concerns about the use of technology to support the curriculum were voiced. Faculty \#4 emphasized, "I think it is important to get the technology correct because students expect so much [from technology] today and will push back when it doesn't function properly."

\section{Theme 6: A national network community of faculty working on the same goals provides unique opportunities for professional development}

One of the unique features of the Quantway program is that it works across schools as part of a formal Networked Improvement Community (NIC). Faculty share experiences, learn from each other, and suggest improvements on a regular basis. They can communicate via online tools, monthly calls, and an annual summer institute. This network provides invaluable opportunities for faculty to grow professionally as well as strengthen the Quantway pathway for all faculty 
and students. As creator and coordinator of the pathway, the Carnegie Foundation has an opportunity to learn what works for whom and under what conditions.

Faculty reported that being part of the NIC was an important aspect of being involved in the entire program. Many individuals were motivated by the opportunity to be involved in a national project to improve math instruction. This impact was illustrated by the following:

Faculty \#2: I think being involved in something on this scale is very important and exciting. I might be able to change how math is taught in college. I am very involved and I'm glad I am; I feel very good about it.

Faculty \#1: Our new college president stated that one of the reasons she came to our college is we're a Quantway college!

In addition to the national recognition, being part of the NIC allowed them to find others who were "like-minded" with similar professional goals and ideas about teaching. Faculty \#5 highlighted the importance of being able to "talk with other colleagues with the same passion" which was "something they hadn't had before." This interaction with other individuals was especially important at the beginning of teaching Quantway. Faculty \#2 commented that "I feel better that there is someone out there I can rely on as opposed to doing this by myself."

Faculty found the online discussions were helpful at sharing ideas, but did wish that they were more active. Faculty \#2 noted, "The forums can be very helpful when people get involved. I wish more individuals shared things... it counts a lot." Faculty reported that they look forward to the National Forum each summer as an opportunity to share ideas and bond with other math faculty.

Faculty also commented on Carnegie's role of being the hub of the network. They felt encouraged by the staff at Carnegie and felt that there was a unique relationship between the faculty and the foundation. Faculty \#7 stated, "the professional development goes both ways; we learn from each other. They [at the Carnegie Foundation] respect what is going on in our classrooms." However, this relationship was sometimes difficult as staff at Carnegie transitioned positions and oft times requested a lot of the faculty member. One frustration expressed by Faculty \#2 was that "we need the people in Carnegie in the same position for longer times. It is difficult dealing with different people so frequently."

\section{Discussion and Conclusion}

While the sample size is relatively small and widespread conclusions may not be drawn from their interviews, we believe this diverse sample of instructors teaching Quantway helps us begin to understand the complexity of teaching a developmental math course based on quantitative reasoning. These eight faculty teaching Quantway offer a complimentary portrait about their experiences using the curriculum both within the classroom and in developing quantitative 
instruction. Faculty \#1 commented that "the excitement, engagement, and appreciation of some students is very rewarding," and Faculty \#8 reported that "teaching Quantway has given me a renewed passion for teaching." The interviewed faculty spoke to positive changes in their own perspectives about teaching mathematics as well as their perception that student attitudes have changed as well. Further, Quantway has offered them opportunities to develop pedagogical skills and gave those working in the pathway a sense of belonging to a network with a common goal. Faculty appreciated being part of the improvement process including adapting the materials to their local needs and sharing strategies that worked with peers across the nation.

Although these benefits are significant, the work in Quantway did not come without challenges. Students needed to learn how to actively participate and collaborate in a mathematics classroom. Faculty evolved into their new roles in the mathematics classroom learning how to manage groups, lead discussions, and motivate and encourage students. The Carnegie Foundation had to learn how to host a NIC which was sometimes difficult during periods in which the materials and personnel were changing. These struggles are ongoing but have led to improvements in how we get students through their mathematics requirements.

An important step in the future of this pathway will be addressing the transition of students exiting the course and moving into subsequent math classes. Faculty will need to prepare students for working in varied learning environments that may not match their experiences in Quantway.

Continued growth in the program will create challenges for both faculty and the NIC. Careful attention to a dynamic curriculum must be maintained as the pathway looks to expand both on existing campuses and at new locations.

Our future research will be to expand the number of voices speaking about the impact of Quantway on stakeholders. Incorporating representative feedback from students will provide a clearer picture of where the pathway succeeds or falters. Firsthand experiences can complement the ongoing research at Carnegie, which is looking at institutional data to determine if student success persists through subsequent courses and if the challenges produce a greater reward in students' quantitative reasoning abilities.

\section{Acknowledgments}

We would like to thank the Carnegie Foundation for the Advancement of Teaching for providing us access to the network of Quantway faculty to choose interviewees.

\section{References}

Attewell, P., D. Lavin, T. Domina, and T. Levey. 2006. New evidence on college

remediation. Journal of Higher Education 77(5): 886-924.

http://dx.doi.org/10.1353/jhe.2006.0037 
Bailey, T., D. W, Jeong, and S. Cho. 2010. Referral, enrollment, and completion in developmental education sequences in community colleges. Economics of Education Review 29(2): 255-270. http://dx.doi.org/10.1016/j.econedurev.2009.09.002

Blair, R. M. (ed.). 2006. Beyond crossroads: Implementing mathematics standards in the first two years of college. Memphis, TN: American Mathematical Association of Two-Year Colleges. http://beyondcrossroads.matyc.org/doc/PDFs/BCAll.pdf

Burdman, P. 2013. Changing equations: How community colleges are re-thinking college readiness in math. Oakland, CA: Learning Works. http://www.learningworksca.org/changingequations/

Complete College America. 2013. The game changers: Are states implementing the best reforms to get more college graduates? http://completecollege.org/pdfs/CCA\%20Nat\%20Report\%20Oct18-FINALsingles.pdf

Ganter, S. L., and W.E. Haver (Eds.). 2011. Partner discipline recommendations for introductory college mathematics and the implications for college algebra. Washington, DC: The Mathematical Association of America. http://www.maa.org/sites/default/files/pdf/CUPM/crafty/introreport.pdf

Gaze, E. 2014. Teaching quantitative reasoning: A better context for algebra. Numeracy 7(1): Article 1. http://dx.doi.org/10.5038/1936-4660.7.1.1

Gordon, S. 2008. What's wrong with college algebra? Primus 18(6): 516-541. http://dx.doi.org/10.1080/10511970701598752

Hillyard, C. 2012. Comparative study of the numeracy education and writing across the curriculum movements: Ideas for future growth. Numeracy 5(2): Article 2. http://dx.doi.org/10.5038/1936-4660.5.2.2

Madison, B. L. 2014. How does one design or evaluate a course in quantitative reasoning? Numeracy 7(2): Article 3. http://dx.doi.org/10.5038/1936-4660.7.2.3

Rotman, J. (2013. Inside a new life: A grand vision for developmental mathematics. MathAMATYC Educator 4(3): 27-35.

Van Campen, J., N. Sowers, and S. Strother. 2013. Community College Pathways: 20122013, Descriptive Report. Stanford, CA: Carnegie Foundation for the Advancement of Teaching. http://www.carnegiefoundation.org/resources/publications/communitycollege-pathways-2012-2013-descriptive-report/ 